\title{
COCO (2017): UNA APROXIMACIÓN INFORMACIONAL A LA VIDA DESPUÉS DE LA MUERTE
}

\section{Coco (2017): An informational approach on life after death}

\author{
Hans CONTRERAS-PULACHEE ${ }^{1,2,3}$; Lucía GOMEZ-SAENZ1; Anie S. SORIANO-ABAL ${ }^{1}$; Alonso ZORRILLA ${ }^{1}$; \\ Jeel MOYA-SALAZAR ${ }^{1,2,4}$ \\ ${ }^{1}$ Escuela de Medicina Humana, Facultad de Ciencias de la Salud, Universidad Privada Norbert Wiener, Lima (Perú). \\ ${ }^{2}$ Grupo de Investigación en Neurociencias Aplicadas-GRINA, Universidad Privada Norbert Wiener, Lima (Perú). \\ ${ }^{3}$ Centro de Desarrollo Integral RINCONADA, Lima, (Perú). ${ }^{4}$ Hospital Nacional Docente Madre Niño San Bartolomé, \\ Lima (Perú). \\ e-mail: jeel.moyasalazar@icloud.com; jeelms@outlook.com
}

Fecha de recepción: 5 de abril de 2019

Fecha de aceptación: 23 de junio de 2019

Fecha de publicación: 15 de septiembre de 2020

\begin{abstract}
Resumen
Se plantea la respuesta a una pregunta que hasta el día de hoy es muy discutible, ¿̇hay vida luego de la muerte? En este documento daremos una respuesta desde la perspectiva de la Teoría Sociobiológica Informacional. Para esto precisamos momentos exactos de la película Coco (2017), en el cual gracias al cine se puede dar aplicación a esta teoría, cabe indicar primero que en la película hay dos aspectos de un mismo lado. Una vida como información social y una vida como sistema psíquico consciente, entonces el momento clave que nos sirve como ejemplo para explicar este fenómeno es cuando el personaje "Chicharrón» desaparece del mundo de los muertos cuando nadie en el mundo real lo recuerda, sin embargo cuando la anciana "Coco» recuerda a su padre fallecido "Héctor», este logra revivir informacionalmente. A su vez también señalamos y felicitamos la buena calidad gráfica en los detalles que caracterizan la animación. En síntesis, vamos a decir que, en efecto, sí, existe la vida (informacionalmente hablando) después de la muerte. Y esto porque cuando aparecemos en el mundo empezamos a vivir como información social, entonces nacemos, y nuestra vida como información social crece en complejidad creciente.

Palabras clave: cine; animación; sociobiología; información; conciencia; información social.
\end{abstract}

Rev. Med. Cine. 2020; 16(3), 175-183 Ediciones Universidad de Salamanca / @@@ J. Med. Mov., 2020; 16 (3), 175-183 


\begin{abstract}
We propose the answer to a question that until today is very questionable, is there life after death? In this document we will give an answer from the perspective of the Sociobiological Informational Theory. For this we need exact moments of the movie Coco (2017), in which this theory can be applied, thanks to the cinema. It should be noted first that in the film there are two aspects of the same side. A life as social information and a life as a conscious-psy- chic system, then the key moment that serves as an example to explain this phenomenon is when the character "Chicharrón» disappears from the world of the dead when no one in the real world remembers. However, when the old "Coco» remembers her deceased father "Hector», he manages to revive informationally. At the same time, we also indicate and congratulate the upright graphic quality in the details that characterize the animation. In short, we are going to say that, indeed, yes, there is life (informationally speaking) after death. And this because when we appear in the world we begin to live as social information, then we are born, and our life as social information grows in increasing complexity.

Key words: cinema; animation; sociobiology; information; conscience; social information.
\end{abstract}

Ficha técnica

«Empiezo a comprender que detenerse es empezar a morir».

Santiago Pajares

Título original: Coco.

País: Estados Unidos.

Año: 2017.

Dirección: Lee Unkrich, Adrián Molina.

Música: Michael Giacchino.

Fotografía: Animation, Matt Aspbury, Danielle Feinberg.

Montaje: Steve Bloom, Lee Unkrich.

Guion: Adrián Molina, Matthew Aldrich (Historia original: Lee Unkrich, Jason Katz, Matthew Aldrich, Adrián Molina).

Intérpretes: Anthony Gonzalez, Gael García Bernal, Benjamin Bratt, Alanna Ubach, Renée Victor, Ana Ofelia Murguia.

Color: color.

Duración: 109 minutos.

Género: Animación, comedia dramática, fantasía, musical.

Sinopsis: «Miguel es un joven con el anhelo de convertirse en leyenda de la música a pesar de la prohibición de su familia. Su pasión le llevará a adentrarse en la "Tierra de los Muertos" para conocer su original legado familiar» (FILMAFFINITY).

Productora: Pixar Animation Studios / Walt Disney Pictures.

Premios: Dos Premios Oscar: Mejor largometraje de animación y mejor canción (2017); Globos de Oro: Mejor filme de animación (2017); Premios BAFTA: Mejor película de animación (2017); Premios Annie: 11 premios incluyendo mejor película, dirección y guion (2017); Círculo de Críticos de Nueva York: Mejor film de animación (2017); National Board of Review (NBR): Mejor film de animación (2017); Critics Choice Awards: Mejor largometraje animado y canción (2017); Satellite Awards: Mejor film animado (2017); Sindicato de Productores (PGA): Mejor película de animación (2017); Asociación de Críticos de Chicago: Mejor film de animación (2017).

\section{Enlaces:}

https://www.filmaffinity.com/es/film893369. html

https://www.imdb.com/title/ tt2380307/?ref_=fn_al_tt_1

Tráiler

Rev. Med. Cine. 2020; 16(3), 175-183 Ediciones Universidad de Salamanca / ॠ@ J. Med. Mov., 2020; 16 (3), 175-183 


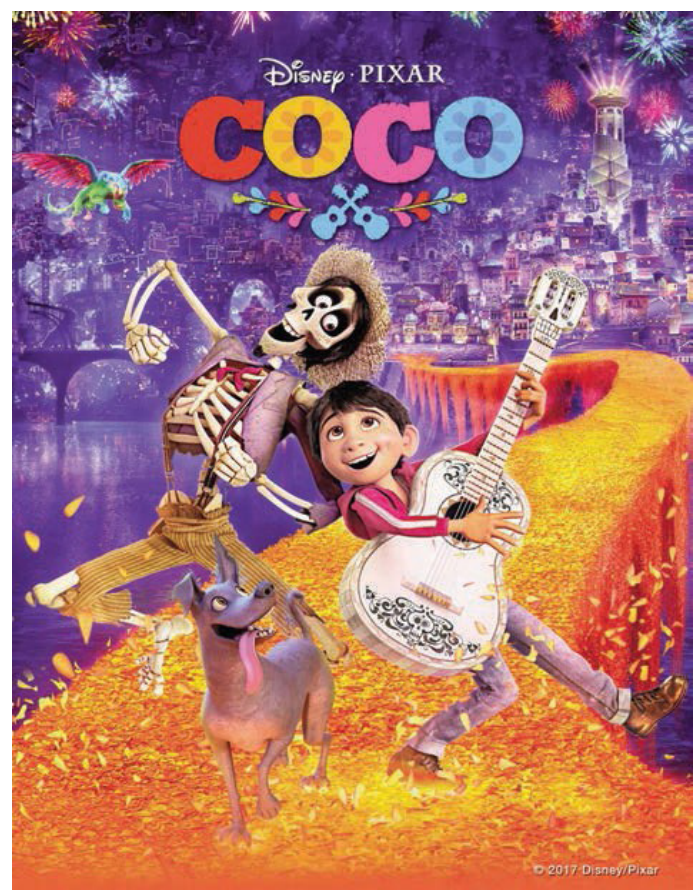

Cartel español.

\section{Introducción}

Empecemos preguntándonos: ¿Existe vida después de la muerte? Diremos que frente a esta pregunta imposible no se puede elaborar una respuesta sino, a lo mucho, relatar una posición. Mencionaremos, a modo de sintetizar, pero a riesgo de caricaturizar, esencialmente, dos posiciones: la posición del creyente y la posición del científico. Luego elaboraremos una propuesta particular, alternativa, de corte informacional ${ }^{1}$.

Se puede decir, como el creyente, que sí, en efecto: existe vida después de la muerte; pero esta respuesta (que es en realidad una posición) parece formularse más «con el corazón» que «con la cabeza $»^{2}$. Y se puede decir como el científico que no existe o que, no se puede afirmar nada preciso (científicamente) frente a la pregunta. Creemos que el dilema profundo de esta forma de creer y de hacer ciencia (que son posiciones "frente a la vida») es no haber definido la vida, por eso se entrampan en afirmar que la muerte es el «finalizar de la vida». Y, nada que ver. Nada que ver.

Basta una revisión de la Teoría Endosimbiótica Serial de Lynn Margulis (1938-2011) para comprender que la vida, desde que apareció (aunque «aparecer» no es el verbo) sobre la tierra no ha finalizado nunca ${ }^{3}$. Que, desde la primera bacteria, que se estableció sobre el mundo «inerte», la vida no ha hecho sino replicarse y mantenerse diversificada, y diversificándose, pero única (siempre continua) desde el inicio hasta ahora. $Y$ «ahora» quiere decir "ahora mismo» que se prosan estas líneas. Ahora que discurren los ojos del que lee. Toda la vida integrada en un mismo, y único, sentido. Un sentido de apuesta (de ruptura, de "bypass») frente al orden inerte: natural.

Entonces, no hay dicotomía entre lo muerto (lo inerte, lo sin vida, lo natural) y la vida: todo es una continuidad, un flujo constante. No hay individuo ni especie(s). La vida es una irrupción en el orden entrópico de las reacciones fisicoquímicas: la vida no es el carrito chocón de las moléculas. La vida es materia organizada, no ordenada, a partir de información. Aquí vamos a asumir una posición alternativa, sostenida en la Teoría Sociobiológica Informacional (TSI) de Pedro Ortiz Cabanillas, desarrollada en el Perú desde 1960 hasta el $2011^{4}$. Desde aquí, vamos a definir la vida como la información. La vida es información. La información es una estructura material que tiene la capacidad de organizar a la materia. La materia inerte puede ordenarse, pero tienen al desorden, al caos, entrópicamente. La información permite que un poco de materia se organice. Es decir, envuelva al orden / desorden, lo imprima de una noción de complejidad y sistema.

En el orden / desorden de la naturaleza, la vida desafía la tendencia natural de las cosas (la entropía), neguentrópicamente estructura niveles de complejidad. La vida es complejidad. Ante la pregunta poco refinada: cuál es la diferencia entre Rev. Med. Cine. 2020; 16(3), 175-183 Ediciones Universidad de Salamanca / @®@ J. Med. Mov., 2020; 16 (3), 175-183 
un gato y una piedra, habrá que decir (no responder, no se trata de dar una respuesta, se trata de evidenciar una posición), que el gato es un ser complejo, la piedra no. Y más puntualmente, los seres humanos al aparecer (aunque "aparecer» no es el verbo) en el mundo somos una continuidad, y desde esta perspectiva el nacer no es más que uno de los eventos circunstanciales más importantes en el curso vital de una persona, y de modo más específico: los seres humanos al cesar nuestra presencia en el mundo (lo que se dice vulgarmente: cuando nos morimos) somos, o por lo menos inauguramos: la posibilidad de un seguir viviendo: ya no con latidos y presiones arteriales, ya no con reflejos psicogalvánicos, ya no con actividad nuclear, cortical, consciente-epiconsciente, ya no como discurso personal ejecutándose; sino por el contrario como información social.

Detengámonos a considerar lo antes referido, stop. Así como ya definimos información como la estructura material que organiza la naturaleza e inaugura la vida, definamos ahora (ya que existen filéticamente cinco tipos de información, la última es): la información social.

La información social es toda estructura material externa a las personas, a los sujetos, que toma una forma en el curso de los últimos, por lo menos, 30 mil años. Podría rastrearse este principio hasta hace 70 mil años, pero sea como fuere, este principio tuvo un origen, y desde entonces no ha parado de sucederse: a esto se le denomina sociedad. Es decir, la sociedad es una estructura material histórica, con una edad, que es obra y gracia del ser humano «moderno». Esto incluye el año 2019 después de Jesucristo, aun cuando este Jesucristo no sea probablemente el Jesucristo del mundo vulgar que se rige por un calendario que no coincide con el 0 del nacimiento del Jesucristo histórico ${ }^{5}$.

Cuando una persona muere, entonces, queda como información social. Mucha de esa información social se creó en el curso de vida de la persona, siempre externo a ella, siempre por fuera. Es obvio que en ese afuera se refleja la existencia de un "adentro», pero esta dicotomía adentro/ afuera es engañosa. Porque, en realidad, el afuera está envolviendo. Dicho en sistémico: envuelve sin tocar, la sociedad es lo periférico de los sujetos. No hay un adentro porque hay un afuera (ni al revés); no hay un adentro ni hay un afuera. La sociedad envuelve, pero no toca, es un sistema cerrado. Los sujetos, las personas, son asimismo sistemas cerrados, epigenética y cinéticamente cerrados ${ }^{6}$.

Piénsese en el siguiente hecho: todo lo que pueda estimular a un ser humano entra por el nivel celular. Sobre este nivel celular se establece una complejidad de 5 niveles que es enteramente cerrada. Por eso no se debe extrapolar de la célula a la conducta, porque entre ambos hay cataclismos de diferencias sustanciales. Lo que la persona vive en el curso de su vida personal, su vida consciente, su vida mental, es un sistema cerrado a la sociedad (en ese sentido, para hacerse consciente, lo social debe recrearse).

La información social es supraindividual, envolvente a cada persona, pero cada persona, desde su nivel celular, puede recrear información social y principiar la vida psíquica consciente (que es lo que nos diferencia del macaco, de la vaca, de ave más astuta y del mamífero más emocional). Esta información social existe como un correlato del máximo nivel de organización de la vida: la información psíquica consciente. Pero lo que precisamos aquí es que cuando dicha información psíquica consciente cesa, con la muerte de la persona, la información social persiste (en nuestros discursos, en nuestros actos y en nuestras obras). Así hasta que, ya no como información psíquica consciente sino como información social, desaparezca: ya sea porque desaparecen todos los registros de la persona, ya sea porque nadie nos recuerda, es decir cuando formamos parte del olvido (el olvido es la desaparición de la información social).

La información social es siempre externa al sujeto, más específicamente: supraindividual, es decir lo envuelve. Es, stricto sensu, los recuerdos de los otros (es decir: las redes neurales de la 
conciencia en todo aquel que nos ha conocido), en lo que un otro le diga a otro otro (es decir: en la estructura del lenguaje). La muerte es un evento circunstancial. Desde que nacemos (incluso desde antes) empezamos a inaugurar una vida que nos habita y que habitamos: en las memorias de los que nos cobijan, y luego, en nuestras propias producciones, como las pinturas en las paredes cuando somos chicos, nuestros primeros escritos, los garabatos, los trazados punteados sobre las letras y los números, nuestros cuadernos escolares, nuestras pinturas, nuestros «mapas mentales», nuestros diarios, nuestros paleles de trabajo, los premios que hemos ganado y perdido.

Y también en las fotos en las que salimos, en los retratos y en las pinturas, en las obras musicales que creamos (imagínese a Nietzsche y piénsese en sus composiciones musicales), en los poemas, en los cuentos (imagínese a Cortázar y piénsese en sus composiciones prosaicas, es indudable que Cortázar siempre estará "vivo» mientras se lean sus cuentos y probablemente toda su obra), en las actuaciones, en las grabaciones que capturan nuestra presencia temporal (imagínese y piénsese en el cine mudo: Charlotte está vivo eternamente en sus películas), etcétera. Es decir, desde que nacemos inauguramos una existencia que nos envuelve. A toda esta forma de vida le llamamos: la vida como información social.

Esta vida como información social trasciende o, precisemos, puede trascender, a la muerte. Para lo cual la muerte, como todo nacimiento, no es más que uno de los eventos circunstanciales más importantes en el curso vital de una persona, y más puntualmente: los seres humanos al cesar nuestra presencia en el mundo (lo que se dice vulgarmente: cuando nos morimos) somos, o por lo menos inauguramos la posibilidad de un seguir viviendo.

\section{Consideraciones intempestivas}

Ciertamente, si vemos así las cosas, nos salta un enorme incidente: ya no es solo que se haya quemado la biblioteca de Alejandría, es algo más contemporáneo, algo más sucedáneo. Y dice así, muchos de nuestros antepasados no tienen vida como información social. Y de esto, precisamente, trata la película Coco (2017).

Puede que, para otros, este film trate de otras cosas. Celebramos, y afirmamos que toda interpretación es válida. Luego proseguimos: muchos de nuestros antepasados no tienen vida como información social puesto que nos hemos olvidado completamente de ellos, no existen ya, quizá murieron cuando murieron, o quizá murieron luego de haberse muerto, y poco después cuando no quedó nadie que los recordara, es decir que los imaginara y los pensara, cuando desaparecieron todos los registros de sus trazos psicomotrices, todas sus cartas y retratos, todas sus fotografías, todos los registros, i.e. cuando se borró de la historia finalmente su presencia. En otras palabras, cuando se acabó la información social (porque la información social se puede acabar: a esto ya no le llamamos muerte: la muerte ya pasó, a esto le llamamos: olvido).

Por eso, Coco es un momento para recordar el siempre esfuerzo heroico de luchar contra un destino inevitable: luchar contra el olvido. El héroe de Coco no es el niño Miguel, ni el perro Dante, ni esa colección de huesos llamada Héctor, sino una mujer anciana, llamada Coco (aunque no sabemos su nombre real, solo que se llama así: (Coco) que está de punto de morir (y que antes de su muerte: florece). Y con el florecimiento rompe el hechizo del olvido, y estira, por lo menos por un tiempo más la memoria colectiva, es decir: la vida como información social (Foto 1).

Cierto: todo ser humano puede vivir, pero no todo ser humano llega a sobrevivir (a vivir como información social). Ejemplos de sobrevidas: vidas como información social: Jesucristo (no importa si el del calendario o el «real»), Buda, Platón, Sócrates, Hipócrates, Descartes, Caravaggio, Darwin, Freud, Mozart (no importa si el del efecto o el

Rev. Med. Cine. 2020; 16(3), 175-183 Ediciones Universidad de Salamanca / @®@ J. Med. Mov., 2020; 16 (3), $175-183$ 
«real»), Cézanne, Marx, Picasso, Hegel, Leonardo, Nietzsche, Kurt Cobain, Frida Khalo, Michael Foucault, Albert Einstein (etcétera y resaltar la presencia del nombre para ese (post)etcétera). Y en específico: esta es la razón también por la que los más crápulas siguen viviendo: porque los recordamos. La mejor forma (por no decir la única forma) de olvidar es no recordar (dejar que el tiempo borre toda memoria), solo así desaparece la información social.

Porque recordar es imaginar y pensar, informacionalmente hablando, es recrear. Cuando recordamos a Napoleón lo estamos inventando, es decir: lo estamos recreando. Lo mismo cuando recordamos a Walt Whitman, lo hacemos existir más como información social, entonces crece, aumenta.

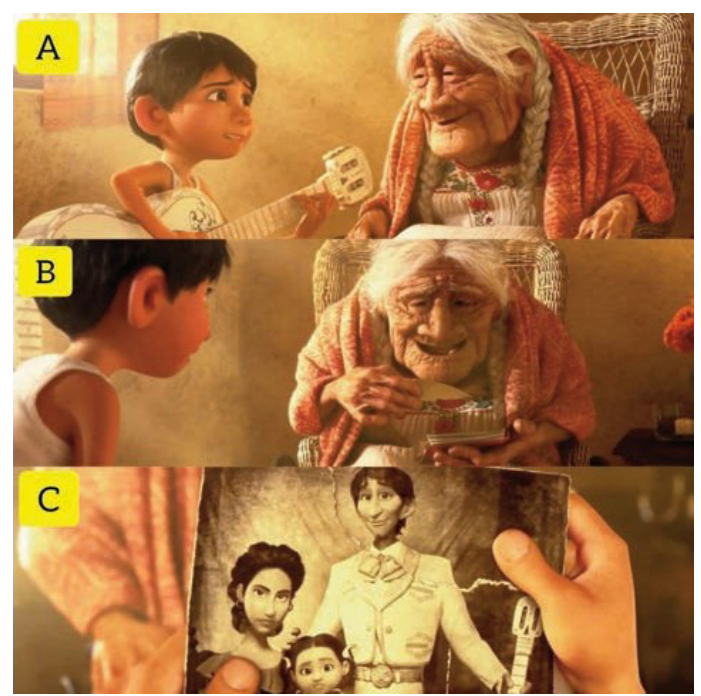

Foto 1. Estiramiento de la Información Social. A) Miguel toca la canción "Recuérdame» para mamá Coco y ella recuerda que su padre Héctor solía cantarle esa canción. B) Abre un cuaderno que contiene poemas, cartas, y C) el pedazo faltante, que es la cara de Héctor, en la foto familiar.

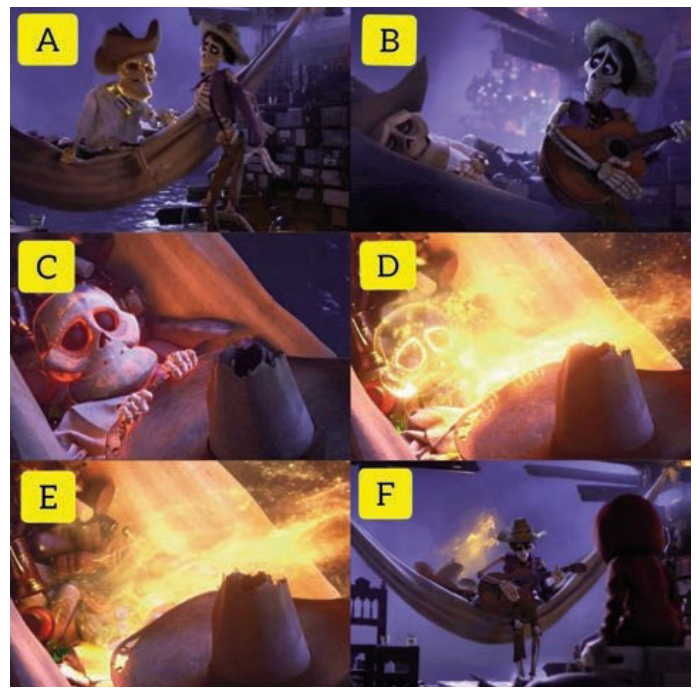

Foto 2. Desaparición de la Información Social. A) Chicharrón (Chi en inglés) le reclama a Héctor por su fémur, pero se da cuenta que está siento olvidado, B) entonces le pide que le toque su canción favorita, finalmente (C, D, E, F) se ve el proceso de desaparición de Chicharrón ante los ojos de Héctor y Miguel.

En este momento, la pregunta ya no es: ¿existe vida después de la muerte? Estamos ante un espacio carente de tiempo. Nuestra consideración es: muchos de nuestros antepasados no tienen vida como información social. Y sí. Ciertamente, cada uno de nosotros, carga a sus espaldas una enorme presencia olvidada.

Entonces, ¿dónde está nuestra tatarabuela más antigua? 0 sin irnos tan lejos: ¿dónde está el tatarabuelo del abuelo? Y seguramente aquel personaje, que ya no está, que fue olvidado, tuvo su perspectiva del mundo: su modo de concebir el amor (su Juanita nocturna, de claro y medialuna, de pudor y aventura, por eso dice la canción en alguna parte del film: "conoces ya, a Juanita... sus ojos son bicolores... sus dientes chuecos, y tiene tres... "), la política, incluso su propia forma explicativa de las cosas y su propio consuelo. Pero, ¿dónde está? Respondemos (y de algún modo retomamos la pregunta inicial): no está. Ya está 
muerto «muerto». Ya se olvidó. Desapareció como información social.

Le pasó lo que le pasa a Chicharrón («Chi», en inglés) en el film, luego de ese último trago existente solo en el mundo de los muertos (Foto 2). O, mejor dicho, lo que fue información social (y que trascendió a la muerte del «hombre») y que volvió a ser estructura material natural, inorgánica. Precisemos ahora, la información social es el único tipo de información que existe de modo supraindividual, es decir, por encima (por «afuera») del sistema vivo que lo cobija, que lo alberga. Y el fenómeno vivo no tiene final sino un inicio: que principia con las bacterias, y luego un continuo iryvenir hasta que, en los últimos 30 mil años (cuando menos) ha establecido un quinto nivel de complejidad: la sociedad.

El primer nivel de información: los sistemas celulares: el segundo nivel de información: los sistemas tisulares: el tercer nivel de información: los sistemas neurales: el cuarto nivel de información: los sistemas psíquicos: el quinto nivel de información: los sistemas conscientes (que son los únicos que tienen un correlato material que los envuelve como sistemas vivos: la información social) ${ }^{6}$. Es decir: la información social existe sobre la base de la información psíquica consciente. Por eso es que vivimos en nuestras obras, por ejemplo.

Precisamos algunos puntos más sobre la película Coco. Ciertamente no es la primera vez que el cine animado busca inspirarse en las tradiciones latinoamericanas. Sin embargo, este film, muestra varios rasgos diferenciales: ora en términos de imagen y tratamiento de la animación, ora en términos del argumento y el desarrollo de la trama (Foto 3). En Coco asistimos a un fenómeno interesante. El título no hace referencia al personaje principal de la película. Por todas partes se promociona un film con la imagen de un niño y su perro (que, si llamamos perro al «bulldog», entonces es mejor llamar a Dante: lobo, pues perro no es). Empezamos entonces a ver la película y en efecto, el personaje aparente es Miguel, el niño de las imágenes del marketing (de la propaganda, de la promoción, eso que, como aquí, juega con nuestros afectos). Y junto con Miguel: Dante, el lobo latinoamericano que existe desde antes de la inclusión abrupta de Latinoamérica en el contexto mundial globalizante. En torno a Miguel, sus padres, y con ellos, casi con la edad presente de una montaña, la figura ancestral que pronto nos enteramos que se llama Coco. Que la primera intuición (la de estar viendo una película sobre un niño llamado (oco) se desvanezca, es uno de los impactos que produce el film en el espectador.

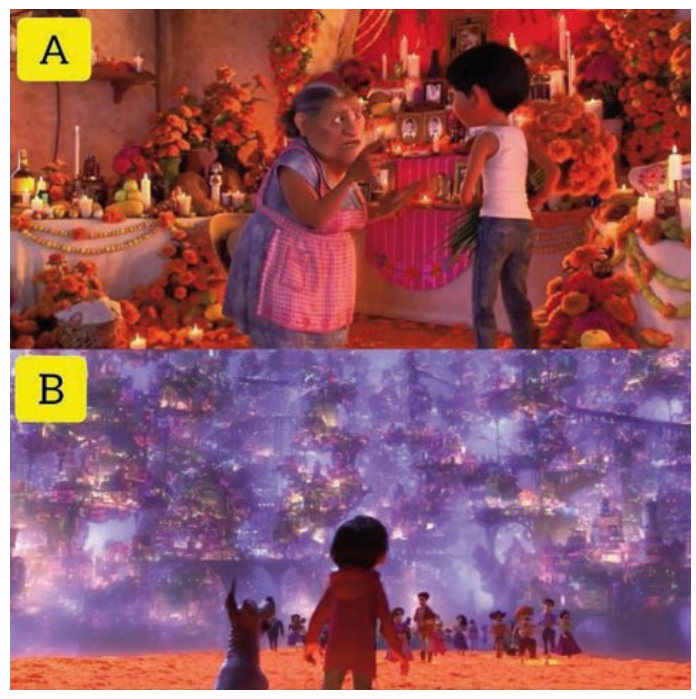

Foto 3. Calidad de Gráficos en la animación «Coco». Nótese la calidad y detalles que caracterizan la animación, en las cuales resaltaremos $\mathbf{A}$ ) el altar de muertos de la familia, y B) el mundo de los muertos.

Más cuando se piensa que el público objetivo de este film son niños y niñas, que en su edad fílmica probablemente no llegan a elaborar aún una estructura sintagmática propia sino una aproximación esencialmente: afectiva ${ }^{7}$. Uno de los atributos de valor del film es que nos muestra con lujo de detalles (verbigracia del uso de una moderna tecnología de animación): la posibilidad de vivenciar el mundo del «más allá», el «mundo de los muertos», el mundo que, según la tradición, existe y es habitado por todos los muertos que recordamos (Foto 3).

Rev. Med. Cine. 2020; 16(3), 175-183 Ediciones Universidad de Salamanca / @®@ J. Med. Mov., 2020; 16 (3), 175-183 
En nuestros términos, este mundo que evidentemente está vivo (por lo menos tan organizado y legislado como el mundo de los vivos), es en realidad, la vida como información social. Más allá de la celebración del día de los muertos, hecho que juega una pieza clave en la trama argumental de la película, vamos a quedarnos con el hecho siguiente, todo el que muere, según la estructura sintagmática del film, repetimos todo el que muere, va a la tierra de los muertos, y permanece ahí hasta que (en vida) todos lo olviden, o lo que es lo mismo: nadie lo recuerde. Esto queda registrado en el film con total maestría. "Coco» pone en evidencia que la vida en la tierra de los muertos no es una vida eterna; es decir, nuestra vida después de la muerte depende de la postergación del olvido. La escena de Chicharrón es quizá uno de los goces más absolutos que nos ofrece Coco (Foto 2).

Digamos más de Chicharrón: personaje, a quien ya nadie recuerda, y está a punto de desaparecer de la tierra de los muertos (en nuestros términos: está a punto de desaparecer como información social). Entonces le pide a Héctor que le cante su canción preferida. $Y$ entonces este entona al ritmo de una suave guitarra el himno a Juanita, y finalmente, en el clímax de la escena, mostrado de cuerpo entero, Chicharrón afirma: por última vez, para morir para siempre en el film (porque ya nadie lo recuerda, ya nadie lo imagina, ya nadie piensa en él): «Me mueven mis recuerdos». Como diciendo: mientras vivimos, vivimos, movemos nuestra vida, y al morir solo vivimos cuando nos recuerdan, cuando nos mueven quienes nos imaginan y piensan, quienes nos recrean como información social.

\section{Conclusión}

Dicho en informacional: cuando nacemos inauguramos una vida que nos envuelve. Hay dos aspectos de un mismo lado. Una vida como información social y una vida como sistema psíquico consciente (mental, si se quiere para utilizar un término corriente). Al morir, esta vida consciente se termina. Sin embargo, mientras estamos vivos, esta vida consciente se puede reflejar supraindividualmente. Hemos dicho que este reflejo puede ser: nuestros retratos, nuestros dibujos, nuestros poemas, nuestras cartas, nuestras fotografías, nuestros videos, nuestros escritos, es decir, en síntesis, el recuerdo de los otros y nuestros testimonios. Si la muerte representa el cese de la vida consciente, al mismo tiempo representa la independencia, el nacimiento de la vida enteramente como información social.

Finalmente, para responder otra vez a nuestra pregunta inicial, esta vez en términos de la película, vamos a decir que, en efecto, sí, existe la vida después de la muerte. Y esto porque cuando aparecemos en el mundo empezamos a vivir como información social, entonces nacemos, y nuestra vida como información social crece en complejidad. Hasta que nos sucede la muerte y se termina (aunque "terminar» no es el verbo, desvanecerse no es acabarse) nuestra vida consciente (nuestra vida creadora de información social). Entonces, la muerte es el nacimiento, la independencia de nuestra vida como información social (en términos de la película: al morir nacemos como información social, la información social es, en parte, la tierra de los muertos; mejor dicho: la tierra de los muertos de Coco es información social). Cada vez que recordamos creamos información social. Si recordamos a Buda estamos creando a Buda como información social, recreándolo, y con esto lo hacemos existir. Con cada biografía que se escriba sobre Chaplin estaremos recreando a Chaplin con información social, lo mismo cada vez que se vean sus películas, lo estamos recreando: como información social. Así, lo hacemos existir, lo hacemos vivir después de la muerte.

\section{Referencias}

1. Ortiz P. Psicobiología Social (Tomo 1). 1 Ed. Lima: Fondo Editorial de la Universidad de Ciencias y Humanidades; 2017. 
2. Chakraborty R, El-Jawahri AR, Litzow MR, Syrjala KL, Parnes AD, Hashmi SK. A systematic review of religious beliefs about major end-of-life issues in the five major world religions. Palliat Support Care. 2017; 15(5): 609-622.

3. Margulis L. Symbiotic Planet: A New Look at Evolution. New York: Basic Books; 1998.

4. Contreras-Pulache H, Moya-Salazar J. In Memoriam: Pedro Ortiz Cabanillas (1933-2011). CNPs. 2019; 13(2): 187-8.
5. Rigby G. The God Secret. New York: Eloquent Books; 2009.

6. Ortiz P. El Sistema de la Personalidad. 2ed. Lima: Fondo Editorial de la Universidad de Ciencias y Humanidades; 2016.

7. Contreras-Pulache H. Neurología Fílmica: el descubrimiento del cine a lo largo de la vida. Lima: Fondo Editorial de la Universidad de Ciencias y Humanidades; 2016.

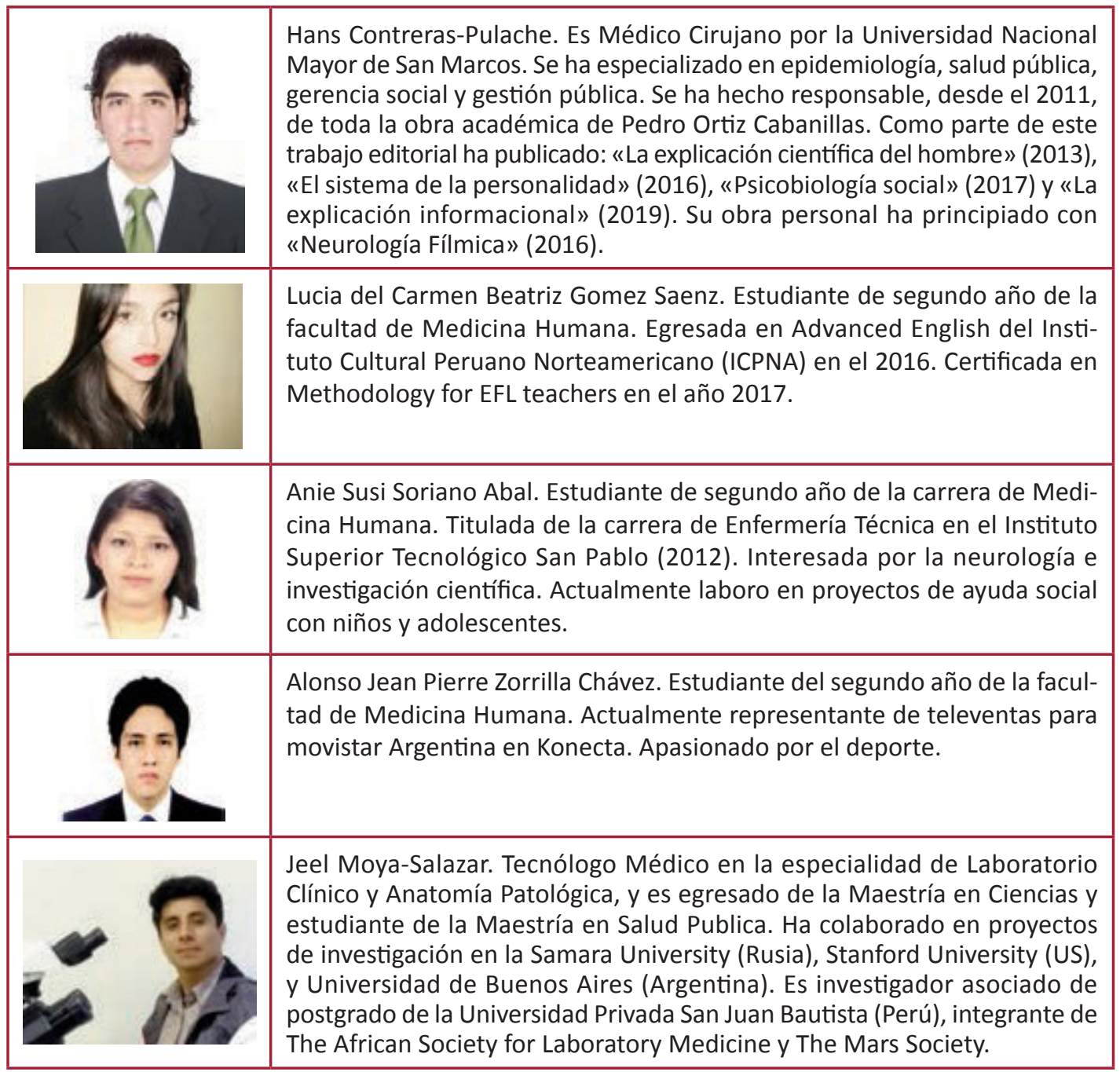

Rev. Med. Cine. 2020; 16(3), 175-183 Ediciones Universidad de Salamanca / @@

J. Med. Mov., 2020; 16 (3), 175-183 